\title{
Erratum to: Sodium fluoride influences calcium metabolism resulting from the suppression of osteoclasts in the scales of nibbler fish Girella punctata
}

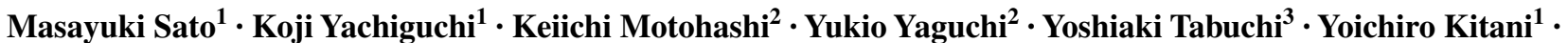 \\ Takahiro Ikari $^{1} \cdot$ Shouzo Ogiso $^{1} \cdot$ Toshio Sekiguchi $^{1} \cdot$ Tran Ngoc Hai $^{4} \cdot$ Do Thi Thanh Huong $^{4} \cdot$ Nguyen Viet Hoang $^{5}$. \\ Makoto Urata $^{1,6} \cdot$ Hiroyuki Mishima $^{7} \cdot$ Atsuhiko Hattori $^{8} \cdot$ Nobuo Suzuki $^{1}$
}

Published online: 23 May 2017

(C) Japanese Society of Fisheries Science 2017

\section{Erratum to: Fish Sci}

DOI 10.1007/s12562-017-1086-0

In the original publication, under section "Effects of $\mathrm{NaF}$ on scale osteoblastic and osteoclastic activities (in vivo experiment)" the first sentence should read as:

Before $\mathrm{NaF}$ or saline $(0.9 \% \mathrm{NaCl})$ injection, the scales on the right side were removed under anesthesia with $0.04 \%$ of 2-phenoxyethanol (Wako Pure Chemical Industries, Ltd.).

The online version of the original article can be found under doi:10.1007/s12562-017-1086-0.

Nobuo Suzuki

nobuos@staff.kanazawa-u.ac.jp

1 Noto Marine Laboratory, Institute of Nature and Environmental Technology, Kanazawa University, Ogi, Noto-cho, Ishikawa 927-0553, Japan

2 Electron Microscope Center, Tokyo University of Agriculture, Tokyo 156-8502, Japan

3 Division of Molecular Genetics Research, Life Science Research Center, University of Toyama, Sugitani, Toyama 930-0194, Japan

4 College of Aquaculture and Fisheries, Can Tho University, Can Tho, Vietnam

5 Department of Science and Technology, Center of Application and Information, Camau, Vietnam

6 Institute of Noto SATOUMI Education Research, Noto-cho, Ishikawa 927-0553, Japan

7 Department of Dental Engineering, Tsurumi University School of Dental Medicine, Yokohama 230-8501, Japan

8 Department of Biology, College of Liberal Arts and Sciences, Tokyo Medical and Dental University, Ichikawa, Chiba 272-0827, Japan 